\title{
humanidades
}

Revista humanidades

Julio-Diciembre, 2015 • Volumen 5, número 2 • ISSN 2215-3934 • pp. 1-21

\section{La literatura de ciencia ficción: Una mirada al futuro en tiempo presente}

DOI: http://dx.doi.org/10.15517/h.v5i2.21211

\section{Óscar Gerardo Alvarado Vega}

Doctor en Estudios de la Sociedad y la Cultura. Profesor Catedrático en la Escuela de Estudios Generales de la Universidad de Costa Rica.

Correo electrónico: oalvarado@gmail.com 


\section{La literatura de ciencia ficción: Una mirada al futuro en tiempo presente}

\section{Resumen}

La literatura de ciencia ficción ha intentado dar cuenta de su Palabras clave: Ciencia entorno, a partir de una mirada hacia el futuro, por lo cual se ha constituido en una manera de hacer literario presente que procura lanzar una mirada hacia los grandes retos del ser humano en su hacer cotidiano, pero sin dejar de lado las grandes preocupaciones que de igual forma comporta el ser humano: la ecología, la ciencia, la sobrepoblación, los miedos, los retos, lo éxitos. Sin dejar de lado lo que representa "echar un vistazo" más allá de nuestro planeta, este tipo de literatura, de monstruos, de extraterrestres, de adelantos y de retrocesos, se convierte en tema importante dentro de la nueva literatura costarricense, por lo cual, dar una mirada a sus orígenes y a lo que representa, es también conocer su vitalidad actual.

\section{The literature of science fiction: A look to the future in the present tense}

\section{Abstract}

Science fiction literature has tried to account for its environment from a look into the future and becomes a way of making literary attempts to describe the major challenges facing humanity, without neglecting the essential concerns of human beings: ecology, science, overpopulation, fears, challenge, successes. This literature monsters, aliens, advances and setbacks, it is important theme in the new Costa Rican literature, take a look, at its origins and what it represents, is also know its vitality.

Keywords: Science fiction, literature, progress, future, context, imaginary. 
"Admitiendo que la ciencia ficción sea en nuestro medio una forma injertada por intereses comerciales, ocurre que no es precisamente inocua. Contra lo que muchos aún creen, sin haberla leído, no es una simple apología de la sociedad industrial. Por el contrario, en sus muestras más lúcidas y representativas, suele acentuar los conflictos internos de esa sociedad, de modo que una lectura hecha desde la dependencia puede llegar a ser sumamente inquietante"

Pablo Capanna

Cuando se habla de ciencia ficción, inmediatamente debe diferenciarse de la literatura fantástica, en tanto esta última responde a la ruptura del orden establecido y reconocido, para dar lugar a lo inadmisible en el seno de lo cotidiano, de acuerdo con Roger Callois.

Es la posibilidad del conejo que habla con el ser humano, y comparten aventuras y reflexiones, toman tragos juntos, y construyen casas y edificaciones, por ejemplo. Por su parte, en la literatura de ciencia-ficción, y en su linde con lo fantástico, pero con un enfoque diferente; aparecen los viajes a la luna, la presencia de lo selenitas, los animales que son propios de la luna y que hablan, entre otros. 
La literatura de ciencia ficción, a la par de los avances científicos -y es eso es lo que le da presencia-, expresa los deseos del ser humano, sus temores en relación con estos avances, lo mismo que su visión en torno a estos. El pensamiento de lo inmediato no se pierde, pues tiene vigencia aún en esa perspectiva de lo futuro. La ciencia y la tecnología acompañan al ser humano y se convierten en tema de la escritura.

Cabe resaltar que el primer texto de ciencia ficción, mal llamado así por lo demás, fue La historia verdadera de Luciano de Samósata. Este escritor griego del segundo siglo después de Cristo, narra la historia de dos marinos que después de navegar ochenta días llegan a una isla que señala los límites de los viajes de Hércules y Dionisio. Un torbellino los arrastra hasta la Luna, donde encuentran animales muy parecidos a buitres, caballos, arañas más grandes que una isla y jinetes que cabalgan en pulgas. Los hombres se casan con hombres, y los selenitas mantienen una batalla con los habitantes del Sol por el planeta Venus. El cielo se tiñó de rojo y los aventureros volvieron a la Tierra, luego son tragados por una serpiente marina para ser llevados a una isla subterránea donde se encuentran con las almas de los filósofos y los héroes. La historia termina y promete una continuación que no se conoce.

Ahora bien, Julio Verne, en el siglo XIX, es uno de los primeros autores que desarrollan este género, aunque sus textos son más especulación que otra cosa. No obstante, el tema de la Luna, de los viajes, entre otros, se hallan desde los orígenes del ser humano, por lo menos desde los primeros textos registrados: un viaje a la Luna, pero en patos. La invasión a la Tierra por parte de otros seres, los viajes en el tiempo, la exploración de otros planetas, viajes a estrellas lejanas, encuentros con seres espaciales desconocidos, tele transportación, y demás, son parte de estos. 
En este contexto de escritura, lo verosímil científico juega un papel importante. De alguna forma, la ciencia ficción se lee como una pre-visión del futuro, y ocasionalmente algunos textos han referido a acontecimientos que luego han tomado vigencia: la bomba de Hiroshima, catástrofes atómicas o contaminación, entre otros.

Es así como las revistas de ciencia ficción adquieren gran relevancia durante los cincuentas, a pesar de que ya desde las primeras décadas algunas tenían un enorme éxito. Luego la recesión estadounidense condena a algunas a la desaparición, pero el género sigue vigente. Galaxy es una de estas, ya que refiere a temas como la contaminación, la Revolución Industrial, los viajes espaciales, por mencionar algunos temas.

También estos textos, y específicamente la ciencia ficción, refieren a importantes avances como la luz fría atómica y la esterilización, o la mutación de elementos, metales y otros. De tal manera que el holocausto no es el tema único en su desarrollo como tal.

Así pues, podemos señalar al menos dos tipos de ciencia ficción: La que no enfatiza en lo científico y la que sí lo hace. El género, como tal, se inicia a principios del siglo XX, con Julio Verne y H. G. Wells. En 1898, H. G. Wells escribe La guerra de los mundos, este texto, posteriormente, será utilizado por Orson Wells en un programa radiofónico. Dicha emisión radiofónica tuvo consecuencias horrendas para los oyentes, quienes lo asumen como verdadero: la invasión de los marcianos. Con el tiempo también, surge la idea de que los visitantes extraterrestres pueden ser amigos y traer la paz. 
La primera novela científica de H.G. Wells fue La máquina del tiempo, por definirla de alguna manera, esta se publicó en 1895. Luego, publica otras como La isla del doctor Moreau (1896), El hombre invisible (1897) y Los primeros hombres en la Luna (1901).

Así las cosas, escritores como Julio Verne, específicamente, dieron paso a la proto-ciencia ficción; es decir, a los primeros intentos para dar lugar a lo que, años más tarde, se denominará ciencia ficción. Según Flamarion Cardoso, durante esta etapa surgen temas como la distopía futura o situada en otro mundo, la Luna, seres metamorfoseados por experimentos llevados a cabo, el fenómeno de lo invisible, el contacto con los extraterrestres, los monstruos alienígenas, la suspensión de la vida, seres mesiánicos que actúan en un futuro donde la distopía tiene lugar, entre otros.

Uno de los textos paradigmáticos de Verne, Veinte mil leguas de viaje submarino, publicada en 1870, en su momento gozará de diversas versiones cinematográficas, cuando el celuloide adquiere relevancia fundamental y contribuye, aún más, a la consolidación del nombre del escritor francés.

Los años posteriores a la Primera Guerra Mundial, década de los años veinte, provocan un deseo pleno de escapar de la difícil realidad del momento, deseo que aumenta con los años de depresión de la década de los años treinta. Lo anterior es el caldo de cultivo que posibilitará la existencia de los primeros textos de ciencia ficción. Buck Rogers es uno de estos, lo mismo que Flash Gordon en 1934. 
Su aceptación se da gracias a revistas especializadas en este género. Surge, por ejemplo, Amazing Histories, en 1926 -la edad de oro de la ciencia ficción-, redactada por Hugo Gernsback. Algunos la utilizan para criticar el progreso y la civilización, en tanto avances científicos y tecnológicos, por lo negativo que esto podría traer a la humanidad. En esta revista, "The skyback of space" causa conmoción, ya que habla de viajes interestelares, distancias indescriptibles y aventuras sorprendentes. Con esto se abre la ciencia ficción en los Estados Unidos, pues antes predominaba en Inglaterra.

Durante la década de los treinta, los temas se enfocan en el uso de teorías y descubrimientos científicos. En el relato "El hombre que evolucionó", de Edmond Hamilton, por ejemplo, se menciona el uso de rayos cósmicos. Si bien existen algunos errores en el texto, estos no hacen que los lectores pierdan el interés.

Entre la década de los cuarenta y los cincuenta, se ubica el periodo clásico de la ciencia ficción y el tema predominante es la previsión del futuro. Es precisamente a partir de la mitad del siglo XX, cuando este género empieza a crecer, a expandirse en revistas, posteriormente en la televisión y, años después, en el cine, cuando logra su verdadero despegue. En el caso de la narrativa costarricense, empieza a tomar vigencia en los primeros años del siglo XXI.

Durante la década del cincuenta, emerge un periodo de auge, ya que la prosperidad económica posibilita el flujo de nuevas revistas, tal es el caso de The magazine of fantasy y Galaxy, de gran acogida. En el texto The climbing wave, el tema es la explosión demográfica, lo que trae contaminación y degradación en el hombre, y constituye un aspecto profético de cara al futuro. 
No obstante, es también durante los años cincuenta cuando se ve amenazada la producción de textos de ciencia ficción, debido a la campaña en su contra llevada a cabo por el médico alemán Fredric Wertham, radicado en Estados Unidos. Este personaje consideraba que dichos textos eran una mala influencia para los niños y jóvenes, incluso, que contribuían al aumento de la delincuencia.

Nacen, entonces, grupos de defensa de los cómics o historietas. Se crea el Comics Code, que defiende a estas revistas, pero con la censura o autocensura aplicada para evitar problemas de violencia exacerbada. Así, desaparecen los muertos vivientes, los vampiros, los fantasmas, la licantropía; aunque con el paso de los años regresan y el código como tal pierde vigencia.

En la segunda mitad de la década de los sesenta, los temas son la civilización, la tecnología y la ciencia, con la problemática del hombre en la tierra. Luego aparece el New Wave, que da paso a la expresión de temas tabú como el de las relaciones sexuales y raciales. Visiones peligrosas, de 1967, es una antología que da cuenta de esto, fue publicada por Harlan Ellison.

Ya alrededor de 1968, la ciencia ficción hard refiere a otros temas: mutantes, poderes extrasensoriales, enfoques sociológicos y psicológicos (Flamarion Cardoso, 2001). Así, con la aparición de películas como Odisea del espacio, en 1968 (en donde las máquinas se vuelven contra su creador, lo cual luego se convertirá en un tema recurrente en películas posiblemente por el temor de lo que la dependencia a lo tecnológico significa), o El planeta de los simios, entre otras, la ciencia ficción aparece de lleno en el texto cinematográfico, esto no la excluye de otras series propiamente de televisión, tales como Perdidos en el espacio. 
Si bien la producción cinematográfica viene desde años atrás abordando el tema de la ciencia-ficción, es con películas como estas que logra delinearse fundamentalmente desde lo que significa este tipo de hacer, y que ha de establecer en adelante una producción cada vez más acelerada en cuanto a número y tiempo de elaboración.

Cerca de la década de los ochenta, se puede ubicar el cyberpunk. Este trae consigo transformaciones del cuerpo, el sexo como factor de destrucción, intrusión e impactos excesivos y devastadores de los medios de comunicación en la vida de los sujetos. La alta tecnología y los bajos niveles de vida toman espacio preponderante en este tipo de expresión. Los hackers tienden a ser sus protagonistas, estos pretenden un mundo más justo y de lucha contra la opresión. Además, existe una preocupación por el control sobre las personas, la corrupción y la vigilancia que coacciona la libertad de los sujetos.

Se plantea, de esa forma, desconfianza a las nuevas tecnologías y al riesgo que trae el hecho de que las personas se vean esclavizadas por la dependencia ante estas. Toma su nombre de la combinación de cibernética y punk. Es un rechazo a la ciencia ficción clásica que afirma la sospecha en torno al empoderamiento tecnológico del Estado y de las grandes corporaciones desde lo tecnófilo, asimismo, al peligro inminente de la dependencia excesiva.

Actualmente, se abordan temas que revelan no solo la grandeza y miseria del ser humano, sino también sus fuerzas y debilidades, implícitas en su destino. El hombre que todo lo puede en el Universo es derrotado por las máquinas y por seres de otras galaxias o planetas. Se deja de ser el centro. El humano crea máquinas y demás que terminarán por destruirlo. Es la crisis de valores que no es ajena a género alguno. 
En algún momento la ciencia ficción pone en duda los valores de la época. Además, refiere a grandes adelantos de la humanidad, tales como la propulsión electrónica, la propulsión iónica, el empleo de la energía nuclear, la antigravitación, entre otros.

Por lo anterior, el texto de ciencia ficción debe ser verosímil, aunque lo relatado no sea posible; este es uno de sus mayores méritos, éxitos y fortalezas. El lector lee la posibilidad de un mundo que no existe, pero resulta probable y aceptable.

Algunos críticos identifican ciertos matices dentro de la ciencia ficción: la ciencia ficción como tal, ligada a la ciencia; la fantaciencia, en donde la ciencia es apenas circunstancial; la utopía y la ucronía, o sea, el juego de mundos y tiempos ideales, desde donde se critica o se observa la sociedad del momento; y lo insólito, donde las fuerzas ocultas o lo sobrenatural se enlazan verosímilmente con lo real (Castagnino 1971, p.178).

La ciencia ficción no es género, sino una especie, según Castagnino, una fuente. Es fuente porque se nutre de fuentes, según este autor. Las más frecuentes, apunta, son: viajes espaciales, contactos con otros mundos y civilizaciones, viajes en el tiempo, aplicación de hipótesis científicas, desarrollo de seres no humanos gracias a los adelantos cibernéticos, desarrollo de cualidades psíquicas, utopías, ucronías y medicina experimental.

En cuanto a la mimesis, los mejores textos logrados no son los que intentan convertirse en calco de la realidad o la época, como señala José Miguel Odero, sino en dar cuenta de un mundo verosímil, nos apunta, pero no verosímil en tanto "copia" o calco, pues saca a la luz aspectos desconocidos hasta ese momento, que presuponen otro camino no explorado aún. 
Esto por cuanto la literatura es una experiencia virtual, no una traslación a la realidad que le da entorno, sino una forma de leer y entender ese entorno. Según Castagnino, en la ciencia ficción no es vital que lo verosímil sea verdadero, basta con que parezca posible o probable, pero sin admitir falsedad.

En la sociedad actual, las imágenes de la ciencia ficción se vierten en mitos futuristas, apunta Sergio Jiménez Cruz. Es importante, de acuerdo con este autor, notar que la ciencia ficción se liga en gran medida con la literatura por cuanto es a partir de esta que, durante el siglo XX, vive su mayor época de apogeo.

Este hacer, ya cinematográfico ya literario, puede contribuir a adaptar la mente a los cambios tecnológicos y sociales, de acuerdo con Capanna en su libro El sentido de la ciencia ficción. De allí la relevancia que como tal se le puede otorgar a esta.

Lo cierto es que los temas que aborda la ciencia ficción pueden repercutir, a partir de las grandes preocupaciones de la humanidad: la incertidumbre por el futuro, su destino como tal, la existencia misma, lo incierto del futuro mediato y más a largo plazo. De tal forma, el relato científico puede prometer progreso como salvación, pero sin dejar de lado el espacio de la hecatombe o de lo apocalíptico que puede emerger en la literatura o en el cine, como se presenta en los monstruos tipo Frankenstein, los entes biológicos, los robots que amenazan la existencia del ser humano o la misma dependencia a las máquinas. 
No es de extrañar, entonces, la presencia de lo tecnológico, ya no solo como lo bueno, como el progreso; sino su manifestación desde lo trágico, lo perverso, lo inadecuado: La mosca, El hombre invisible, entre otros. El castigo, por pretender convertirse en un dios creador, sobreviene cuando sus producciones o creaciones escapan a su control. En el futuro las cosas pueden ser posibles, pero no desde la óptica presente aún.

Como señala Raúl Castagnino en su libro Experimentos narrativos:

Sea como fuere, en todo ello hay conclusiones innegables: hoy la conjunción de ciencia, industria y técnica comporta aparente beneficio al hombre, pero real defraudación a lo humano, porque el hombre-masa, producto de tal civilización, acusa indudable mengua de las prerrogativas de la individualidad, asiento de lo humano. Y esas prerrogativas se realizan, fundamentalmente, en la creación, sea a través de la ciencia o de la poesía, del número o del arte (Castagnino 1971, p. 246).

La sociedad ha sido permeada por la tecnología, haciéndola parte indispensable de su cotidianidad; por eso, no es casual que los sueños de ciencia ficción se aceleren con el paso de los años, y cada vez más se piense en adelantos mayores, producto de los grandes inventos de la actualidad, hasta alcanzar lo casi inimaginable o lo impensable. Lo cierto es que, a la par de estos grandes adelantos y avances, nos encadenamos, sin quererlo, y nos hacemos esclavos de nuestra propia tecnología. 
De alguna forma, la propia ciencia ficción, a pesar de su ficcionalidad inmediata, termina por esclavizarnos, hacernos dependientes en tanto seguimos imaginando mundos espeluznantemente avanzados, de cara al futuro mediato y un poco más lejano, gracias a los adelantos presentes e inmediatos.

El término proviene de science fiction, tomado de Hugo Gernsback, editor de la revista Science Wonder Stories, en 1929. Posteriormente, se plantean algunas definiciones más cercanas, como la que brinda John Campbell Jr., otro de los grandes impulsores de este tipo de literatura en revistas, en Astounding Science Fiction:

(...) una literatura cuyos vínculos de semejanza con la ciencia serían metodológicos. La ciencia ficción elabora extrapolaciones que, a partir de la ciencia contemporánea, pretenden explorar hipotéticamente, desde la forma de narrativas literarias, lo que podría ser el futuro, en cuanto a fenómenos nuevos, todavía no descubiertos, las máquinas - es decir, la tecnología- y también la sociedad humana.

Kingsley Amis limita su definición a la literatura, aunque no habría dificultad en extenderla a otras formas de expresión. Para él, la ciencia ficción es un "relato en prosa que trata de una situación que no podría presentarse en el mundo que conocemos, pero cuya existencia se basa en la hipótesis de una innovación cualquiera, de origen humano o extraterrestre, en el dominio de la ciencia o de la tecnología; o se podría decir, de la seudociencia o de la seudotecnología" (Cardoso, 2001, pp. 121-122). 
De igual manera, la ciencia ficción no depende de la idea temporal del futuro y su desarrollo en ese momento para ser considerada como tal, pues puede desarrollarse en el presente o el pasado (la idea del pasado, claro está) si tiene el sostén científico que esta requiere.

En relación con esta idea del tiempo, este ha sido un tema muy explotado por la ciencia ficción, en la medida en que refiere al hecho no solo de la manifestación del ser humano en un tiempo ya ido, un presente o un futuro hipotético, sino también en tanto el viaje al pasado puede predisponer a cambios en la historia y a transformaciones radicales en el futuro mediato e inmediato. Ha sido este uno de los temas que más ha obsesionado el abordaje de cientos de historias y parece aún inagotable. La corta de un árbol, la cacería de una criatura prehistórica, las huellas dejadas en un lugar determinado, pueden ser tan importantes como para virar los acontecimientos propios de la humanidad y altear todo en el futuro.

Lo mítico de la ciencia ficción tiene su referente en el hecho de que, como señala Flamarion, responde a un aspecto de la norma socialmente aceptada, que es la ciencia o la apariencia de esta, para intentar responder a inquietudes que la ciencia del momento aún no puede responder. Es el mismo principio del mito y su intento de explicar el mundo y sus fenómenos. 
Lo cierto es que hoy la ciencia ficción no es ajena a los grandes problemas que afronta la humanidad o a las grandes preocupaciones que enfrenta el ser humano. Esa visión futurista "traslada" a otro tiempo las grandes preocupaciones, como si fuesen irresueltas, y se profundizarán en el futuro.

De esa manera, no se pierde conexión con lo actual ni con las inquietudes que se afrontan hoy: el ambiente, el agua, la ecología, la contaminación, las energías y su uso inadecuado, las guerras, la destrucción de recursos, la soledad, la pobreza, la miseria, la degradación, entre otros. Todos elementos que se perciben en textos narrativos y cinematográficos sumamente apocalípticos.

Los cambios estructurales, económicos, políticos y la creciente tecnología son factores que influyen en la aparición de la ciencia ficción, en sus diversas manifestaciones temáticas. Ahora bien, en ese marco Ciro Flamarion, en su texto Ensayos, señala que los grandes temas son cuatro: Utopías y distopías; anticipación y juego con el tiempo, los pasados y futuros alternativos; las inteligencias artificiales con sus pro y sus contra; y otros mundos, otros seres, en relaciones de encuentro y desencuentro, de diálogo y de distanciamiento.

La utopía es posible para la ciencia ficción en tanto promesa. La distopía es un punto de llegada de gran cantidad de textos literarios y cinematográficos, como espacio en donde lo indeseable termina por tener lugar. Este último quizás predomina en los textos literarios. 
En cuanto al futuro como ubicación en los textos de ciencia ficción, la menor parte de estos han logrado "dar en el clavo" con la construcción de un futuro que se vuelve posible. Esto debido a que en esos textos lo científico y lo tecnológico, apunta Flamarion, han tenido preponderancia.

En cuanto a las inteligencias artificiales, por citar un caso, los cyborgs, es decir, seres humanos parcialmente transformados en máquinas, han ido adquiriendo mayor presencia. Los casos cinematográficos son más conocidos que los literarios y se convierten en tema predilecto dentro de esta industria. De hecho, en el lenguaje cinematográfico el cyborg es el robot revestido de apariencia humana, a diferencia del robot con apariencia de máquina.

Ahora bien, el desplazamiento del ser humano como centro del Universo tiene como uno de sus puntos esenciales el tema del encuentro con otros seres, igual o más avanzados, aunque por lo general se ubican en el primer plano. Es así como en la literatura y el cine, el ser humano viaja a otros planetas o es "invadido" por alienígenas que vienen a conquistar la Tierra. Rara vez se produce un encuentro meramente cordial.

La ciencia ficción es una forma de abordar, interpretar y entender el mundo, en su lógica o en su manifestación irracional. Muchos relatos o novelas abordan este tema desde la visita que efectúan extraterrestres a nuestro mundo, no solo para establecer lazos de amistad o establecer conflictos insalvables. En ocasiones el punto de acercamiento tiene que ver con la visita que efectúan alienígenas simplemente para mirar el caos que provocó el ser humano en el planeta, a pesar de la inteligencia de la cual presumen los habitantes de la Tierra. Desde esa perspectiva, se convierten en textos apocalípticos que dan cuenta del pronto final del ser humano a causa de sus propios actos. 
Se trata de una percepción del mundo, una suerte de filosofía en tanto interpretación y lectura, según cita Capanna en su libro El sentido de la ciencia ficción, ya apuntado páginas atrás.

En relación con uno de los temas predilectos de la ciencia ficción, el encuentro máquina-ser humano, o viceversa, se dice que está en boga:

En la ciencia-ficción actual se ha adoptado la convención literaria de llamar "androides" solamente a los autómatas de naturaleza orgánica (el homunculus de la alquimia), reservando para las máquinas humanoides la designación de "robots"; y para los compuestos de ambos, es decir en el caso de los "cerebros vivientes" de Siodmak y Lewis, que combinan un cerebro humano con un cuerpo mecánico, o viceversa, alguien ha propuesto la palabra "cyborg", formada sobre la base de "cibernética" y “organismo" (Capanna 1966, p. 74).

El mismo Capanna señala que la ciencia ficción explota y explota más las problemáticas colectivas que individuales, y quizás ahí radica su preocupación más científica, enfocada hacia lo colectivo y menos hacia lo particular. Surge, entonces, una duda sobre si los escritores de ciencia ficción profetizan o solo hacen crítica social.

De manera predominante, hoy la literatura de ciencia ficción lee el mundo de manera diferente. Lo positivo o negativo que de eso deriva, es más una visión del mundo y una percepción que la lectura plena de la realidad en tanto imposible reflejo. 
Se debe tener en cuenta que no toda la ciencia ficción apunta siempre a lo mismo. El ejemplo más claro y palpable lo constituye el hecho de que la literatura rusa se preocupa más por el destino del ser humano, por la vida y la muerte; en ese sentido, es una especie de acercamiento más bien filosófico y existencial plasmado en el texto literario. Es así como se reflexiona desde la literatura en torno a grandes problemas que atañan, desde tal punto de vista, al futuro y al mismo presente del ser humano.

En la literatura rusa, incluso la estadounidense, el escritor de ciencia ficción alcanza las mejores obras cuando es además científico. De tal manera, no es lo posible o lo imposible, sino la manera en que construyen el texto. Lo creíble y lo increíble pasan por el tamiz de este hacer literario, ya no solo en el texto escrito, sino también en el ámbito de lo cinematográfico. Así, cala en los lectores y apela a los espectadores.

Hoy, quizás más que nunca, aparece con nuevos bríos y con la fuerza que la propia tecnología y un público ávido le confiere. Los grandes adelantos, pero también el abordaje de perspectivas poco halagadoras, constituyen grandes paradojas en la producción y escritura al respecto, pero quizás el peso máximo se dirige hacia la segunda, con todas las lecturas que implican riesgos que empiezan a derivar en visiones terroríficas ante el futuro mediato e inmediato.

Los nuevos valores de la ciencia ficción permean el tratamiento de los textos, sus temas. La "originalidad y rompimiento" que encontramos en esta implica, en el fondo, una relectura o reinterpretación de los valores tradicionales, una concepción muy diferente de mundo, con perspectiva, por lo general, hacia el futuro. 
La utopía debilita lo establecido en tanto desmitifica un mundo enmascarado y "predice" lo que representa el advenimiento de un futuro desolador. La utopía, como espacio de comodidad y de triunfo del ser humano, deja de tener vigencia y se perfila o presenta un futuro catastrófico:

El escritor de CF se encuentra muy bien situado para observar las contradicciones de su propio mundo, puesto que, como sabemos, se encuentra al margen, en ruptura con su propio mundo; al materializar en su obra una de estas contradicciones de su mundo, suele apostar por el porvenir, pero también apuesta por la muerte de su propia sociedad, de su propio mundo. Que acierte o no es lo de menos, lo de más consiste en que esta apuesta no deja de ser realista y, en algunos casos, revolucionaria (Ferreras 1972, 141).

Por lo anterior, cabe resaltar un espíritu de peso mayormente pesimista en relación con el futuro, al menos por parte de la ciencia ficción. El ser humano desencadena sus propios problemas, los cuales escapan de su control y cobran su precio con el paso del tiempo. Por ejemplo, la explosión demográfica descontrolada se convierte en tema de la ciencia ficción, desde una perspectiva poco halagüeña, y preocupante de cara al futuro. No son pocos los autores que refieren este tipo de tema en sus escritos.

Así pues, los robots, los androides, los viajes en el tiempo, los mutantes, los encuentros con extraterrestres, los superhombres y los universos paralelos, vienen a nutrir la posibilidad de mundos diversos, de acercamientos literarios y cinematográficos de gran vigencia en el imaginario colectivo. 
Es por eso que la ciencia ficción, en definitiva, aflora desde el momento en que se rompen los límites de lo imposible y el ser humano vislumbra posibilidades diferentes hacia el futuro, gracias a los avances tecnológicos, a la ciencia, a la búsqueda insaciable de nuevos mundos y nuevos rumbos:

La ciencia ficción solo pudo comenzar a existir como forma literaria cuando al ser humano le resultó concebible un futuro diferente, un futuro, concretamente, en el que los nuevos conocimientos, los nuevos hallazgos, las nuevas aventuras y mutaciones, conformarían una vida radicalmente alejada de los esquemas familiares del pasado y del presente (Scholes y Rabkin ,1982, p. 17).

Debe quedar establecido que la ciencia ficción no es aplicación de la ciencia, sino que esta última es apenas una excusa usada por el texto literario para, en definitiva, explorar la vida y el espíritu del hombre, como señalan Scholes y Rabkin en La ciencia ficción. Historia, ciencia, perspectiva. Desde tal aserto, debe quedar claro que la literatura no es ciencia, ni la ciencia es literatura, pero una y otra se entrecruzan como disciplinas para conformar esto llamado ciencia ficción. 
Asimov, Isaac. (1982). Sobre la ciencia ficción. Buenos Aires: Editorial

Sudamericana.

Referencias bibliográficas

Capanna, Pablo. (1966). El sentido de la ciencia ficción. Buenos Aires: Editorial Columba.

Capanna, Pablo. (1976). Ciencia-ficción, la otra respuesta al destino del hombre. Buenos Aires: Timerman Editores.

Castagnino, Raúl H. (1971). Experimentos narrativos. Buenos Aires: Juan

Goyanarte.

Ferreras, Ignacio. (1972). La novela de ciencia ficción. Madrid: Editorial Siglo XXI.

Flamarion Cardoso, Ciro. (2001). "La ciencia ficción, imaginario del siglo XX", en Ensayos, pp. 119-196. San José: Editorial Universidad de Costa Rica

Jameson, Fredric. (2009). Arqueologías del futuro. El deseo llamado utopía y otras aproximaciones de ciencia ficción. Madrid: Editorial Akal.

Marranghello, Daniel. (1986). Cine de ciencia ficción. San José: (s.e.)

Sadoul, Jacques. (1975). Historia de la ciencia-ficción moderna (1911-1971).

Barcelona: Plaza y Janés.

Scholes, Robert y Eric S. Rabkin. (1982). La ciencia ficción. Historia, ciencia, perspectiva.

Madrid: Editorial Taurus.

Recibido: 25-Agosto-2015 Aceptado: 11-Septiembre-2015

Todos los derechos reservados. Universidad de Costa Rica. Esta revista se encuentra licenciada con Creative Commons Reconocimiento-NoComercial-SinObraDerivada 3.0 Costa Rica.

Correo electrónico: humanidades.eeg@ucr.ac.cr / Sitio web: http://revistas.ucr.ac.cr/index.php/humanidades 